\title{
RESÍDUOS SÓLIDOS URBANOS: A PERCEPÇÃO AMBIENTAL DOS MORADORES DE PONTAL DO PARANÁ - PR
}

\author{
URBAN SOLID WASTE: THE ENVIRONMENTAL PERCEPTION FROM \\ SOCIAL ACTORS IN PONTAL DO PARANÁ - PR
}

\author{
Carem Jorjiane Mersenburg Gonçalves ${ }^{1}$ \\ Iris Buosi Martinez ${ }^{2}$ \\ Pablo Guilhermino Maichak ${ }^{3}$ \\ Paulo Roberto de Almeida Santos ${ }^{4}$ \\ Sara Priscila Teles ${ }^{5}$ \\ Cesar Silva ${ }^{6}$
}

\begin{abstract}
Resumo
O aumento da geração de resíduos sólidos está intrinsicamente relacionado com o crescimento populacional, os hábitos de consumo, a urbanização e a economia de uma região. Embora existam tecnologias para mitigar os impactos ambientais tais como a segregação e reciclagem de resíduos, o comprometimento dos moradores em realizar o manejo adequado dos resíduos sólidos se torna essencial. Em vista disso, este trabalho teve por objetivo compreender o comportamento dos moradores de Pontal do Paraná, região litorânea do Estado do Paraná, em relação a separação dos resíduos sólidos. Para a obtenção dos dados, 101 indivíduos foram entrevistados aos quais responderam questões sobre segregação de resíduos e meio ambiente, e foram agrupados em grau de ensino formal, idade, sexo e profissão. Observou-se que a percepção ambiental varia de acordo com o grau de instrução dos atores sociais, principalmente pela cultura e o meio social em que vivem. O acesso a um nível educacional maior sugere um comportamento melhor em relação a separação dos resíduos. Para a maioria dos entrevistados, a divulgação das ações ambientais tais como o programa de coleta seletiva é deficiente no município, e não atinge os comerciantes e residentes em relação à segregação dos resíduos gerados. Os resultados sugerem que a gestão ambiental no município não é adequada, e que é necessário a atualização do Plano Integrado de Gerenciamento de Resíduos Sólidos no município.
\end{abstract}

* Artigo Original: Recebido em 09/10/2020 - Aprovado em 22/03/2021.

${ }^{1}$ Acadêmica do curso de Engenharia Ambiental e Sanitária, Universidade Federal do Paraná (UFPR), Pontal do Paraná/PR, Brasil. Brasil.e-mail: carem@ufpr.br ORCID: https://orcid.org/0000-0001-7021-0001

${ }^{2}$ Acadêmica do curso de Engenharia Ambiental e Sanitária, Centro de Estudos do Mar/UFPR, Pontal do Paraná/PR, Brasil. e-mail: irisbuosi@gmail.com ORCID: https://orcid.org/0000-0002-6455-7997

${ }^{3}$ Acadêmico do curso de Engenharia Ambiental e Sanitária, Centro de Estudos do Mar/UFPR, Pontal do Paraná/PR, Brasil. e-mail: guilherminomaichak@gmail.com ORCID: https://orcid.org/0000-0002-9637-9240

${ }^{4}$ Acadêmico do curso de Engenharia Ambiental e Sanitária, Centro de Estudos do Mar/UFPR, Pontal do Paraná/PR, Brasil. e-mail: pauloi.stos13@gmail.com ORCID: https://orcid.org/0000-0002-3491-2687

${ }^{5}$ Acadêmica do curso de Engenharia Ambiental e Sanitária, Centro de Estudos do Mar/UFPR, Pontal do Paraná/PR, Brasil. e-mail: telessarapriscila@gmail.com ORCID: https://orcid.org/0000-0002-9887-3453

${ }^{6}$ Engenheiro Ambiental, MBA em Gestão Ambiental, Especialista em Engenharia de Segurança do Trabalho, Mestrado e Doutorado em Ecologia e Conservação. Docente do Curso de Engenharia Ambiental e Sanitária, Centro de Estudos do Mar/UFPR, Pontal do Paraná/PR, Brasil. e-mail: cesar.silva@ufpr.br ORCID: https://orcid.org/0000-0001-8057-2372 (autor correspondente) 
Palavras-chave: meio ambiente; sustentabilidade; plano integrado de gerenciamento.

\begin{abstract}
The increase the solid waste generation is intrinsically related to population growth, consumption habits, urbanization and the economy of a region. Although technologies exist to mitigate environmental impacts such as segregation and recycling of waste, the commitment of residents to carry out the proper management of solid waste is essential. The aim this work was understanding the behavior population of Pontal do Paraná, coastal region of the State of Paraná in relation to the solid waste. 101 people is analyzed and were grouped in the formal schools, age, sex and professional occupation. It was observed that the environmental perception varies according to the degree of education of the social actors, mainly by the culture and the social environment in which they live. Access to a higher educational level suggests better behavior in relation to waste separation. For most of the interviewees the disclosure of environmental actions such as the selective collection program is deficient and does not affect merchants and residents in relation to the segregation of solid waste generated. The results suggest that environmental management in the municipality is not adequate, and that it is necessary to improve the Integrated Solid Waste Management Plan in the city.
\end{abstract}

Keywords: environment; sustainability; integrated management plan.

\section{Introdução}

São inúmeros os problemas de saúde que estão diretamente ligados a falta de saneamento básico no Brasil. Isso resulta em doenças gastrintestinais, parasitárias, respiratórias, dermatológicas, infectocontagiosas, alérgicas, intoxicações, e muitas outras transmitidas por diversos tipos de vetores (SILVA; YAMANAKA; MONTEIRO, 2016).

Para Egri e Pinfield (1998), existe uma estreita relação com os diversos fatores macroeconômicos e sociais, a exemplo do crescimento populacional, desigualdade da distribuição de renda, entre outros, que contribuem para agravar a saúde pública.

Dentre a problemática moderna devido ao saneamento básico destaca-se a geração de lixo. A palavra lixo significa cinza, vinculada às cinzas dos fogões, sugerindo um produto inservível (ALENCAR, 2005; BRANCO, 2003; MUCELIN; BELLINI, 2008). Porém, em meados da década de sessenta, os sanitaristas passaram a utilizar uma nova denominação para palavra lixo, passando a ser designado como resíduos sólidos, pois os mesmos podem ter serventia tal como o reaproveitamento ou reciclagem (PEREIRA; CURI, 2013; VIRGOLIN; SILVA; SANTOS, 2015).

Em regiões litorâneas essa questão se agrava, uma vez que existe uma população flutuante entre os períodos de alta e baixa temporadas, causando aumento do resíduo gerado transtornos na coleta, acondicionamento e tratamento desses resíduos (SILVA et al., 2020).

Embora muitas iniciativas de soluções para a questão dos resíduos sólidos venham sendo implantadas no país, o gerenciamento do Resíduos Sólidos Urbanos (RSU) ainda encontra dificuldades a ser implementado, pois envolve além das questões ambientais, as sociais e de saúde.

Além disso, segundo os dados da ABRELPE (2020), nos últimos dez anos a geração de resíduos sólidos cresceu 19\%, nesse período ocorreram importantes mudanças no setor de resíduos principalmente em decorrência da implementação dos princípios da Política Nacional de Resíduos Sólidos (PNRS) estabelecida pela Lei 12.305, de agosto de 2010, que estabelece responsabilidades e ferramentas para o gerenciamento dos resíduos sólidos urbanos.

Contudo, os dados mostraram que no ano de 2019 ainda observou-se a disposição inadequada de cerca de 29 milhões de toneladas de resíduos sólidos no país, de um total de aproximadamente 72.747.515 milhões de toneladas, o que constitui um desafio para o poder público para promover um gerenciamento de resíduos eficaz e ambientalmente correto (ABRELPE, 2020). 
Isso evidencia a importância de conhecer as fontes geradoras dos resíduos e sua disposição final, buscando junto à sociedade iniciativas sustentáveis através da participação em programas de educação ambiental para que ocorram mudanças nos padrões de consumo atual.

Neste contexto, é importante avaliar os atores sociais que geram, separam, coletam e dispõem os resíduos sólidos.

A percepção dos atores sociais com o meio ambiente, dependerá do modo como estas pessoas encaram a questão do problema dos resíduos e o método utilizado para resolvê-lo.

De acordo com Melazo (2005), a percepção deve buscar uma harmonia entre os temas políticos, culturais, sociais e econômicos junto à área ambiental, e por fim estabelecer uma inter-relação do homem com o meio em que vive.

Desse modo, a percepção ambiental é avaliada como um parâmetro para mensurar o comportamento da população frente ao meio ambiente (PALMA, 2005; MARIN, 2008). Segundo Rua, Bernardes e Brotto (2015), a percepção proporciona a análise de deformidades morais, visando encontrar estratégias e medidas eficazes para solucionar os problemas do meio ambiente.

Figura 1 - Localização do município de Pontal do Paraná

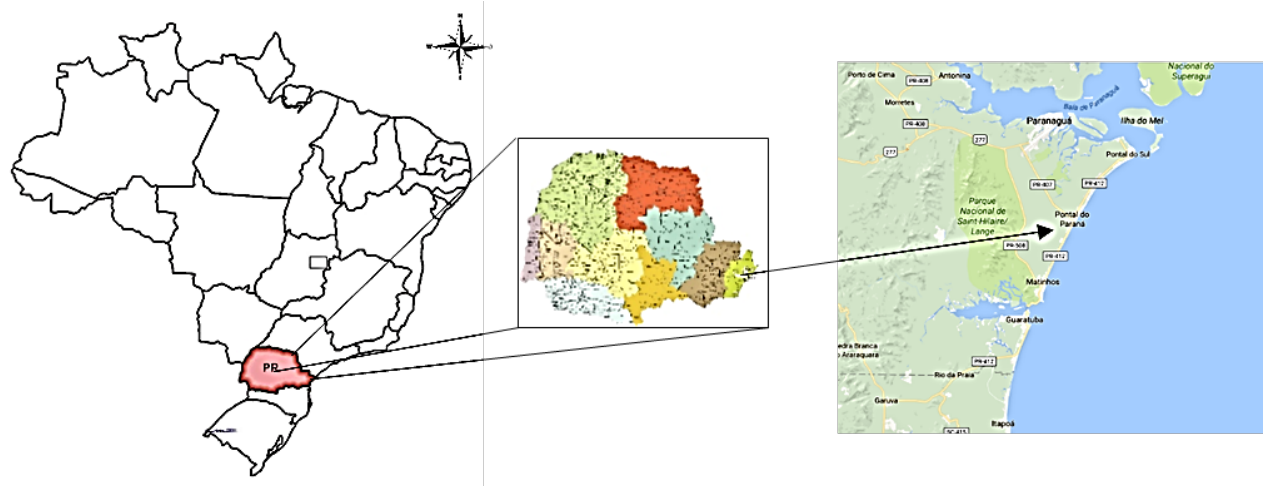

A participação popular e o envolvimento de todos os segmentos da sociedade se tornam necessários para solucionar uma demanda socioambiental cada vez mais importante que é o gerenciamento dos resíduos sólidos, e atender plenamente às diretrizes atuais de proteção ambiental e responsabilidade social, permitindo o conhecimento quali-quantitativo e as peculiaridades dos diferentes resíduos gerados por uma comunidade (OLIVEIRA et al., 2013).

Dentro dos aspectos abordados, o presente estudo teve por finalidade diagnosticar a percepção ambiental dos atores sociais em Pontal do Paraná, município do litoral paranaense, frente aos resíduos sólidos.

\section{Material e Métodos}

\subsection{Local de estudo}

O município de Pontal do Paraná (Figura 1), localizado na região litorânea do Estado do Paraná, tem população de 27915 mil habitantes (IBGE, 2010), no entanto, em época de veraneio esse número aumenta consideravelmente, ocasionando transtornos aos moradores locais devido ao alto fluxo de veículos, geração de resíduos, falta de água potável, entre outros. 
expressar suas opiniões em relação aos programas ambientais do município tais como a coleta seletiva. Além disso, foi questionado sobre a importância da segregação dos resíduos em recicláveis tais como papel, alumínio e plástico e não recicláveis como os restos de comida entre outros, e caso não houvesse separação dos resíduos, quais seriam esses motivos; se os mesmos os separariam se soubessem da existência de um programa de reciclagem municipal; se conheciam qual a destinação final dos seus resíduos gerados; e qual seria a melhor ação necessária para estimular a separação do lixo no município. Como um dos entrevistados era analfabeto, os entrevistadores leram as questões e anotaram as respostas diretamente no formulário.

Para a avaliação dos hábitos dos atores sociais em relação à segregação de resíduos em recicláveis e não recicláveis, os mesmos foram agregados em faixas etárias, profissões e grau de ensino. Os entrevistados não foram identificados e nenhum de seus dados pessoais foram coletados.

\subsection{Análise Estatística}

Para verificar se havia diferenças significativas entre os agrupamentos de dados relacionados à segregação de resíduos, foram aplicados os testes estatísticos não paramétricos de Kruskal Wallis, seguido pelo teste de Wilcoxon utilizando o software Prism Graphpad. Todos os testes tiveram nível de significância $\alpha$ de 0,05 . Para as demais avaliações, os dados foram compilados em frequências \% e absolutas.

\section{Resultados e Discussão}

No total foram entrevistadas 101 pessoas, sendo 53 mulheres e 48 homens. Os estudantes apareceram em maior número (46), seguidos por comerciantes (25), pescadores (17), donas de casa que se autodeclararam “do Lar" (6), e 7 pessoas de profissões diversas. Desses, 50 possuíam idade entre 12 e 22 anos, entre 23 a 32 anos (13), 33 a 42 anos (16), 43 a 52 anos (8), 53 a 62 anos (13), e no grupo de 63 a 72 anos somente uma pessoa foi entrevistada (Figura 2).

Figura 2 - Perfil dos atores sociais entrevistados. A - Faixa etária dos atores sociais. B - Sexo dos atores sociais. C - Formação dos atores sociais. D - Profissão dos atores sociais.
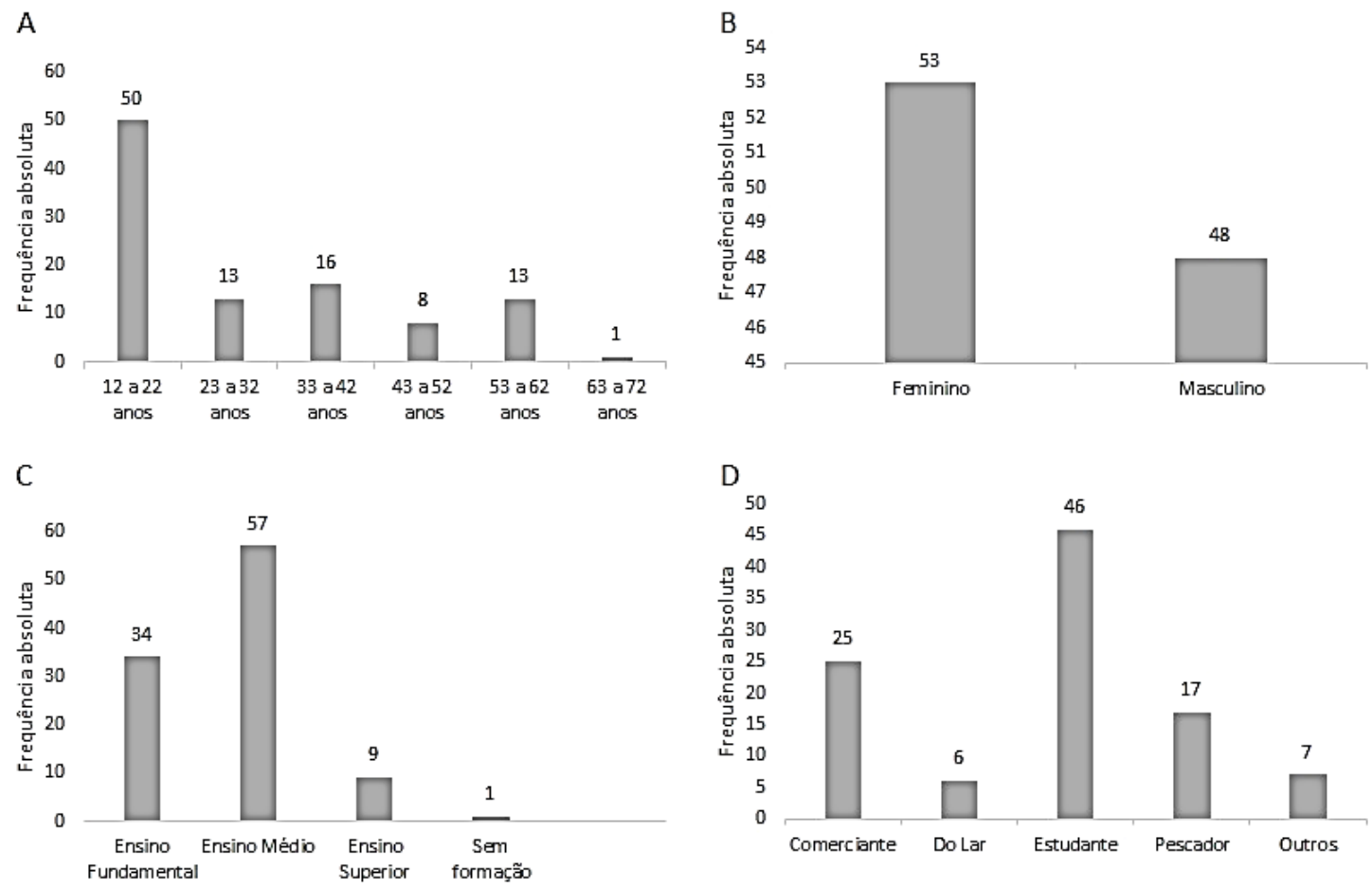

FONTE: Os autores (2020). 
O grupo que cursou até o ensino médio respondeu que, em sua maioria, separa e avalia importante a segregação dos resíduos, corroborando com outros autores que consideram que o nível escolar dos munícipes tende a aumentar a adesão à reciclagem de resíduos (BETANIN; SILVA, 2016; LOVATO; SILVA, 2014; BOCHNIA et al., 2013).

Em relação ao hábito de separar corretamente os resíduos sólidos de acordo com o potencial de reciclagem conforme a faixa etária, o grupo de 12 a 22 anos $28 \%$ responderam que segregam, de 23 a 32 anos $(38,46 \%)$, de 33 a $42 \operatorname{anos}(25 \%), 43$ a 52 anos (50\%), entre 53 a 62 anos (61,54\%). O único ator identificado acima de 63 anos afirmou que não separa os resíduos sólidos entre reciclável e não reciclável (Figura 3A).

A idade parece contribuir com a separação do lixo. Neste estudo, a maioria dos entrevistados com idade entre 53 e 62 anos afirmaram ter o hábito de separar os resíduos gerados em sua residência e/ou comércio, em contraste com o público mais jovem, entre 12 e 22 anos, que responderam não segregar seus resíduos $(p<0,05)$. Esse comportamento dos jovens sugere que, pelo menos para o município de Pontal do Paraná, em suas residências, essa tarefa está atribuída aos seus pais.

Já para a segregação dos resíduos sólidos conforme a profissão, observou-se diferença significativa entre os grupos avaliados $(\mathrm{p}<0,05)$. Os comerciantes responderam que os separam $(\mathrm{p}<0,05 ; 48 \%)$; as donas de casa (do Lar) afirmaram não separar seus resíduos, e $76 \%$ dos estudantes também não o fazem. $41 \%$ dos pescadores asseguraram segregar os resíduos gerados $(\mathrm{p}<0,05 ; 41 \%)$ contra $71 \%$ dos de outras profissões que disseram separá-los (Figura 3B).

Figura 3 - Hábitos de segregação de resíduos sólidos dos atores sociais: A - faixa etária; B - profissão. * p <0,05

A

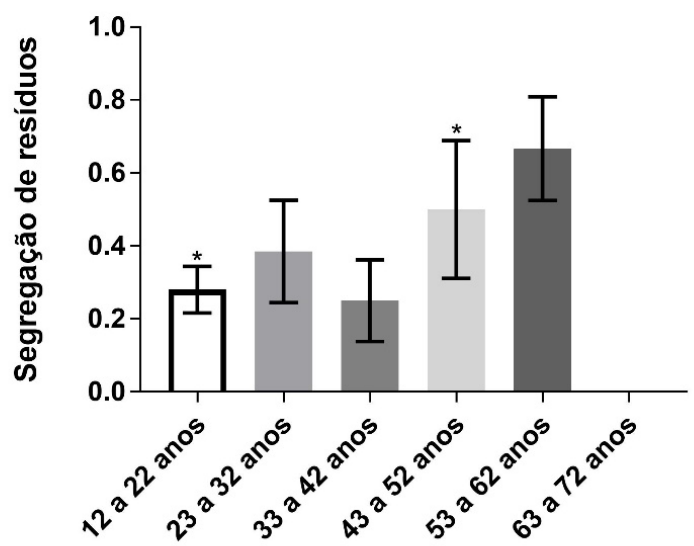

B

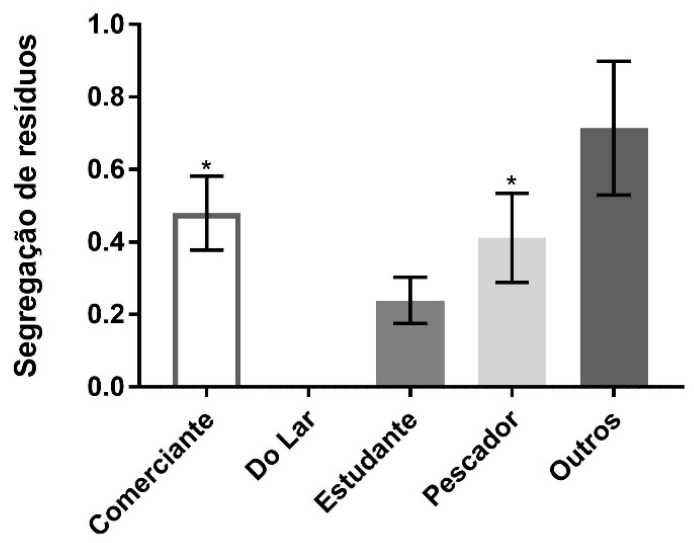

FONTE: Os autores (2020). 
Em relação a nível de escolaridade e a separação dos resíduos sólidos, 44,12\% dos atores sociais que cursaram até ensino fundamental afirmaram que os separam; os que cursaram até ensino médio: 47,37\% e dos que cursaram o Ensino Superior: 55,56\%; e o que não tinha nenhuma formação escolar afirmou que não segrega seus resíduos.

Quando os que não segregavam os resíduos foram questionados por quais motivos não realizavam, $22,77 \%$ responderam por falta de tempo, $38,61 \%$ por falta de um Programa Municipal de Coleta Seletiva, $6,93 \%$ achavam desnecessário e 7,92\% relataram por outros motivos. Quando foram questionados que, se soubessem que havia um Programa de Coleta Seletiva no município, 93\% dos entrevistados afirmaram que passariam a separar, e 7\% ainda não separariam.

Os atores sociais ainda foram avaliados se conheciam o destino dos resíduos gerados na sua residência e comércio: $45 \%$ acreditam que vão para um lixão, 23\% não sabem, $21 \%$ acreditam que vão para um aterro sanitário, 9\% para outros lugares e $3 \%$ para os catadores.

Neste trabalho, observou-se heterogeneidade entre gêneros, idade e profissão dos entrevistados, destacando a importância de uma visão global sobre a percepção dos moradores de Pontal do Paraná sobre os resíduos.

Resíduos sólidos é um dos principais problemas socioambientais que a maioria dos municípios enfrenta, tratando-se de um desafio para o poder público (SILVA; PRZYBYSZ, 2014). A PNRS estabelece diretrizes e ferramentas que implementadas podem facilitar o gerenciamento dos resíduos urbanos tais como o Plano Integrado de Gerenciamento de Resíduos Sólidos (PIGRS).

O PIGRS considera a participação de toda a sociedade na solução do gerenciamento dos resíduos, incluindo assim todos os atores sociais tais como os catadores e suas associações, permitindo uma gestão ambiental inclusiva e democrática (BRASIL, 2010).

Contudo, o grau de escolaridade sugere ser uma variável importante a ser considerada nos programas de gerenciamento ambiental do município.

Neste estudo foi observado que mais da metade dos entrevistados no grupo dos que cursaram o ensino superior $(55 \%)$, relataram que durante a vida acadêmica compreenderam que a segregação dos resíduos era vital para minimizar os impactos ambientais. Essa informação ressalta a importância de temas ambientais estarem inseridos na educação formal.

Apesar de ser um processo simples, a maior parte da população ainda não possui o hábito de separar os resíduos, necessitando em muitos casos de um estímulo para que essa segregação ocorra (PERSICH; SILVEIRA, 2016).

Os comerciantes, contudo, declararam realizar a segregação dos resíduos em seus estabelecimentos e os mantém em lixeiras para recolhimento pelo caminhão de resíduo reciclável que passa uma vez por semana. Nos diálogos com esse público, ficou evidente que a presença de catadores influenciava neste comportamento, pois os mesmos declararam que muitos catadores comparecem com frequência em seus estabelecimentos buscando recicláveis. Os materiais recicláveis são de fonte de renda para muitos atores sociais. Isso promove a inclusão social e minimiza os impactos associados ao descarte inadequado. (BETANIN; SILVA, 2016).

De acordo com Gonçalves (2003), o catador faz a retroatividade entre os aspectos sociológicos, econômicos, políticos, ambientais e sanitários, de forma a sensibilizar a população quanto ao consumo consciente dos recursos.

Os resultados obtidos neste trabalho são semelhantes com os encontrados por Beltrão, Dunta e Nunes (2016), onde 43\% dos entrevistados afirmaram separar seus resíduos.

A Lei Federal n. 9.795/99, dispõe que a educação ambiental esteja presente em todos os níveis de ensino para democratização do conhecimento, uma vez que estes constroem importantes competências para o equilíbrio entre o meio ambiente e os seres que nele habitam (BRASIL, 1999). Entretanto, no levantamento de dados a respeito da segregação dos resíduos através das cores das lixeiras, foi possível analisar uma grande carência na disseminação de informações e ausência de uma educação ambiental voltada aos moradores de Pontal do Paraná uma vez que desconheciam as diferenças entre cores e seus respectivos resíduos.

A segregação de resíduos ainda é um assunto a ser amplamente discutido e divulgado com a população para que se atinja uma adesão massiva da sociedade.

Este trabalho sugere que nem todos os atores sociais entrevistados estão dispostos a segregar seus 
resíduos, talvez por desconhecerem que o município realiza a coleta seletiva por uma cooperativa de catadores, mas que enfrenta dificuldade em atender todos os balneários por contar com apenas um caminhão (SILVA et al., 2020).

Essa falta de percepção é corroborada quando os entrevistados foram indagados se soubessem da existência de um programa de coleta seletiva mudaria este hábito. Quase a totalidade dos atores sociais afirmaram que se soubessem da existência do programa os separariam, demonstrando que o município necessita melhorar seu programa de coleta seletiva, sugerindo que o programa atual de coleta seletiva é ineficiente.

Quando questionados acerca da disposição final dos resíduos sólidos gerados, as respostas eram dadas com pouca certeza. $48 \%$ dos atores sociais mencionaram que a disposição final dos resíduos gerados no município de Pontal do Paraná vai para um lixão a céu aberto, o que não condiz com a realidade, pois o município envia os resíduos coletados para um aterro sanitário desde o ano de 2000 (FIGUERÊDO, 2008), embora o referido aterro esteja passando por sérios problemas de operação. Isso indica que, apesar do aterro estar funcionando há quase duas décadas, a maior parte dos entrevistados ainda não sabe da sua existência.

Este resultado é corroborado com o relatado por Arantes e Fehr (2012), que demonstrou que apenas uma parcela da população, de aproximadamente de $35 \%$, sabe qual o destino do lixo após sua coleta, demonstrando certo descaso da população com o destino de seus próprios resíduos.

Entretanto, tal percepção dos munícipes de Pontal do Paraná pode estar atrelada ao fato do atual aterro sanitário estar funcionando inadequadamente, com disposição dos resíduos em céu aberto e sem cobertura de solo, descumprindo normas legais e de concepção de projeto (SILVA et al., 2020), além de uma deficiência em ações de educação ambiental por parte do poder público.

Em síntese, esse trabalho demonstrou que a gestão municipal no que se refere aos resíduos sólidos necessita melhorar em sua eficiência, principalmente, na educação ambiental de seus munícipes que, em parte, ainda não está consciente da necessidade de sua participação no processo da gestão ambiental. Sugere-se, portanto, que o município atualize seu Plano de Gestão Integrada de Resíduos Sólidos.

\section{Conclusões}

O crescimento populacional desordenado, como evidenciado no município em estudo, afeta o meio ambiente degradando-o e comprometendo a saúde pública.

A percepção dos atores sociais em relação aos resíduos sólidos, demonstrada neste trabalho, mostrou-se heterogênico, variando com o grau de instrução, pelo nível cultural e o meio social em que vivem. Sendo que os de grau instrução mais elevado e os de faixa etária maior são os que mais segregam os resíduos. Percebeu-se que a percepção ambiental de cada ator social entrevistado se assemelha com o grupo ao qual o mesmo está inserido.

Constatou-se durante o estudo que aliado à disposição inadequada dos resíduos está a necessidade de ações de educação ambiental, especialmente no que tange à segregação de resíduos, além da ampliação e melhoria da infraestrutura para os catadores, pois são os principais agentes norteadores.

\section{Referências}

ASSOCIAÇÃO BRASILEIRA DE EMPRESAS DE LIMPEZA PÚBLICA E RESÍDUOS ESPECIAIS - ABRELPE. Panorama dos resíduos sólidos no Brasil 2020. São Paulo: ABRELPE, 2020.

ALENCAR, M. M. M. Reciclagem do lixo numa escola pública do município de Salvador. Candombá, v. 1, n. 2, p. 96-113, 2005.

ARANTES, C. A.; FEHR, M. Destino final dos resíduos sólidos na cidade de Monte Alegre de Minas. Caminhos da Geografia, Uberlândia, v. 13, n. 44, p. 239-248, 2012.

BELTRÃO, M. R. M.; DUTRA, M. T. D.; NUNES, A. T. Percepção ambiental sobre resíduos sólidos: estudo de caso do Conjunto Residencial Pernambuco. Revista Gestão Sustentável Ambiental. Florianópolis, v. 4, n. 2, p. 209-233, 2016.

BETANIN, E.; SILVA, C. A. A reciclagem no município de Rolândia-PR: conscientização é possível. Revista de Ciências Ambientais, Canoas, v. 10, n. 2, p. 45-54, 2016.

BOCHNIA, J.; SANTOS, J. T.; SILVA, A. G.; SILVA, C.A. A gestão de resíduos sólidos gerados no restaurante universitário de uma instituição de ensino superior. Engenharia Ambiental Pesquisa e 
Tecnologia, Espírito Santo do Pinhal, v. 10, n. 2, p. 81-89, 2013

BRANCO, S. M. Ecologia da cidade. 2. ed. São Paulo: Moderna, 2003.

BRASIL. Lei n. ${ }^{\circ}$ 9.795, de 27 de abril de 1999. Institui a Política Nacional de Educação Ambiental. Diário Oficial da República Federativa do Brasil, Brasília, 1999.

BRASIL. Lei n. ${ }^{\circ}$ 12.305, de 02 de agosto de 2010. Institui a Política Nacional de Resíduos Sólidos. Diário Oficial da República Federativa do Brasil, Brasília, 2010.

EGRI, C. P.; PINFIELD, L. T. As organizações e a biosfera: ecologia e meio ambiente. In: CLEGG, S.; HARDY, C.; NORD, W.R. (Orgs). Handbook de Estudos Organizacionais. v. 1. São Paulo: Atlas, 1998.

FIGUERÊDO, C. S. Caracterização físico-química e microbiológica da lagoa de polimento e das lagoas do entorno do aterro sanitário de Pontal do Paraná. 151 f. Dissertação (Mestrado em Sistemas Costeiros e Oceânicos) - Setor de Ciências da Terra, Universidade Federal do Paraná, Pontal do Paraná, 2008.

GONÇALVES, Pólita. A reciclagem integradora dos aspectos ambientais, sociais e econômicos. 1. ed. Rio de Janeiro: DP\&A: Fase, 2003.

INSTITUTO BRASILEIRO DE GEOGRAFIA E ESTATÍSTICA - IBGE. Censo Demográfico 2010. Disponível em: <https://censo2010.ibge.gov.br/>

LOVATO, P. A.; SILVA, C. A. Diagnóstico dos resíduos sólidos domiciliares no município de Rolândia - PR. Revista de Ciências Ambientais, v. 8, n. 2, p. 37-45, 2014.

MARIN, A. A. Pesquisa em educação ambiental e percepção ambiental. Educação Ambiental, v. 3, n. 1, p. 203-222, 2008.

MELAZO, G. C. Percepção ambiental e educação ambiental: uma reflexão sobre as relações interpessoais e ambientais no espaço urbano. Olhares e Trilhas, v. 6, n. 6, p. 45-51, 2005.

MUCELIN, C. A.; BELLINI, M. Lixo e impactos ambientais perceptíveis no ecossistema urbano. Sociedade \& Natureza. v. 20, n. 1, p. 111-124, 2008.
OLIVEIRA, A. S.; OLIVEIRA, C. N.; CORREIA, J. E.; GONÇALVES, L. S.; CARVALHO, M. C. A coleta e a disposição final dos resíduos sólidos urbanos no município de Capim Grosso-BA. In: Feira do Semi Árido. Feira de Santana. Anais eletrônicos. 2013.

PALMA, I. R. Análise da percepção ambiental como instrumento ao planejamento da educação ambiental. Dissertação (Mestrado em engenharia de minas, metalúrgica e de Materiais) - Escola de engenharia, Universidade Federal do Rio Grando do Sul, 2005.

PEREIRA, S. S.; CURI, R. C. Modelos de gestão integrada dos resíduos sólidos urbanos: a importância dos catadores de materiais recicláveis no processo de gestão ambiental. In: Book Gestão Sustentável dos Recursos Naturais: uma abordagem participativa. Campina Grande, EDUEPB, 2013.

PERSICH, J. C; SILVEIRA, D. D. Gerenciamento de resíduos sólidos: importância da educação ambiental no processo de implementação da coleta seletiva de lixo - o caso Ijuí/RS. Gestão, Educação e Tecnologia Ambiental, v. 4, n. 4, p. 416-426, 2011.

RUA, M. B.; P., BERNARDES, L.; BROTTO, D. Percepção do ambiente marinho por crianças no Rio de Janeiro, Brasil. Revista Biociências. V. 21, n. 1, p. 27-44, 2015 .

PARANÁ. Secretaria de Estado do Turismo do Paraná. Regiões turísticas do Paraná. Disponível em: <http://www.turismo.pr.gov.br/Turista/Pagina/ Regioes-Turisticas-do-Parana $>$

SILVA, C.; PRZYBYSZ, L. C. B. Sistema de Gestão Ambiental. 1. ed. Curitiba: Intersaberes, 2014.

SILVA, C. A.; YAMANAKA, E. H. U.; MONTEIRO, C. S. Monitoramento microbiológico da água de bicas em parques públicos de Curitiba (PR). Engenharia Sanitária e Ambiental, v. 1, n. 1, p. 1-5, 2016.

SILVA, C. A.; CORREA, A. O.; FIGUEIREDO, M. V. O.; PRANDINI, M. K. Análise da geração de resíduos sólidos em Pontal do Paraná, litoral paranaense. In: SILVA, H. C. Engenharia Ambiental e Sanitária: Interfaces do Conhecimento 3. 1. ed. Atena Editora, 2020, p. 1-11.

VIRGOLIN, I. W. C.; SILVA, E. M. T.; SANTOS, R. A. Relato da experiência sobre o projeto profissão catador: O lixo como fonte de trabalho e cidadania. Revista Dialogo, Canoas, n. 31, p. 13-29, 2015. 